\title{
DOSSIÊ
}

Sociologias, Porto Alegre, ano 17, no 39, mai/ago 2015, p. 224-246

\section{A secularização conduz à decadência mopal?}

\section{Resumo}

Os debates sobre ética e religião, sobre a significância da fé na mediação dos valores e da coesão sociais, e sobre os riscos das religiões para a tolerância e a coexistência pacífica tendem a ser distorcidos em razão de deficiências empíricas. Os argumentos, em geral, se fazem de um modo que poderíamos denominar "a priori". Neste artigo, proponho uma abordagem "empírica", querendo dizer com isso uma atitude que envolva um mínimo de vieses conceituais, que vá além do a priori e esteja aberta à riqueza dos fenômenos histórico-culturais.

Palavras-chave: Ética e religião. Sociologia Moral. Secularismo.

"Universidade de Berlim (Alemanha) 


\section{Does secularization lead to moral decline? ${ }^{1}$}

\section{Abstract}

Discussions on ethics and religion, on the significance of faith in the mediation of values and social cohesion, and on the risks posed by religions to tolerance and peaceful coexistence tend to be biased because of empirical shortcomings. Arguments are generally made in a way that we could call "a priori". This paper offers an "empirical" approach, meaning thereby an attitude that involves a minimum of conceptual biases, one that goes beyond the a priori and is open to the wealth of historical and cultural phenomena.

Keywords: Ethics and religion. Sociology of morality. Secularism.

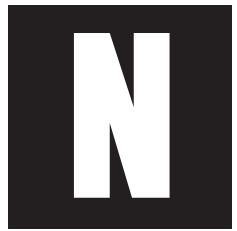

o âmbito da teoria social, têm havido amplos debates públicos sobre religião e ética, sobre a importância da fé para a transmissão de valores e para a coesão social, e sobre os riscos resultantes das religiões para a tolerância e a convivência pacífica. Todos esses debates padecem, muitas vezes, de um déficit empírico. Seus participantes, normalmente, argumentam de forma "a priori". Isto é, a partir de uma suposta essência da religião de maneira geral, ou da fé cristã em particular, eles estabelecem de antemão tratar-se de algo imprescindível ou perigoso; o mesmo ocorre com aqueles que, de modo similar, tiram conclusões abrangentes à luz de seu entendimento da razão como tal e, por conseguinte, tentam demonstrar a superioridade de uma justificação moral racional ou decla-

\footnotetext{
'Este artigo consiste na tradução de uma versão ligeiramente modificada do segundo capítulo do livro "Glaube als Option - Zukunftsm.glichkeiten des Christentums". Herder, Freiburg/Basel/ Wien, 2012.

Tradução: Gerson Roberto Neumann (UFRGS). Revisão: Regina Vargas
} 
Sociologias, Porto Alegre, ano 17, no 39, mai/ago 2015, p. 224-246

ram que o objetivo de seus argumentos é demonstrar os limites fundamentais de tais justificações.

Não tenho qualquer pretensão de desvalorizar os complexos argumentos filosóficos desenvolvidos por ambos os lados desse debate, mas sugiro um procedimento mais empiricamente orientado. Evidentemente, uma abordagem "empírica" não significa assumir ingenuamente que podemos produzir soluções incontestes para questões filosóficas, com suas dimensões inevitavelmente normativas, a partir de descrições factuais. "Empírico", aqui, significa uma atitude que envolva mínimas pré-concepções conceituais, que vá além do apriorístico e esteja aberta à riqueza dos fenômenos histórico-culturais. No que concerne a esta atitude, tomo como modelo na área de pesquisa sobre religião e valores o grande filósofo pragmatista e psicólogo americano William James, particularmente sua obra clássica de 1902 "The Varieties of Religious Experience". ${ }^{2}$ Nesse livro, ele buscou, inicialmente, distanciar-se de toda pressuposição dogmática no campo dos Estudos da Religião - fossem elas de natureza teológica ou secular -, simplesmente evitando tomar como base doutrinas ou instituições religiosas e focando, ao invés, nas dinâmicas da experiência religiosa, que são meramente interpretadas nos ensinamentos religiosos e aplicadas e organizadas através das instituições religiosas. Com isso, ele escolhia um ponto de partida que superava a oposição entre "crentes" e "não-crentes", pois a partir dessa perspectiva mesmo os descrentes têm acesso - pelo menos imaginário - às experiências que ele analisou, as quais em meus textos denomino de experiências de autotranscendên-

${ }^{2}$ JAMES, William. Die Vielfalt religiöser Erfahrung (1902). Frankfurt/Main, 1997.

N.T. Trata-se de William James (Nova lorque, 11/01/1842 - Tamworth, 26/08/1910). O livro "Variedades da Experiência Religiosa" é o resultado de uma compilação de palestras de James sobre "Teologia Natural", publicado em 1902. 
cia (JOAS, 1997; 2004). No desenvolvimento de sua pesquisa, James foi extremamente cauteloso em conferir a cada uma de suas afirmações o princípio de falibilidade, ou seja um status empiricamente refutável ou suplantável. Por exemplo, ao enfatizar que os grandes modelos de ascetismo e atos heróicos de descentramento moral, até então, teriam sido encontrados exclusivamente entre pessoas com motivações religiosas, ele tratou de formular isso de modo a evitar excluir dogmaticamente a possibilidade de que indivíduos sem motivação religiosa pudessem vir a desempenhar no futuro atos similares de ascetismo e heroísmo moral, ou de que tais casos já tenham ocorrido no passado, mas não tenham sido suficientemente analisados. O século XX, com seus feitos "heroicos" a serviço de ideais seculares - da nação, da vitória da raça ariana, do comunismo - certamente teria conduzido James a modificar sua tese; minha proposta seria a de referir ao sagrado, em lugar do que James propóe como motivação religiosa, deixando claro que os ideais sagrados e ímpeto emocional deles decorrente também podem estar associados a conteúdos seculares (JOAS, 2011).

No âmbito das controvérsias religiosas contemporâneas, tal posição "empírico-filosófica" (Arnold Gehlen) é recomendável não somente por razões metodológicas gerais, mas por uma razão específica relacionada à atual constelação político-religiosa. Uma das teses fundamentais que defendo é a de que o momento histórico em que nos encontramos e no qual discutimos sobre questões religiosas está determinado pela morte de duas certezas aparentes. A primeira dessas certezas foi discutida em outra ocasião ${ }^{3}$, e se refere ao fato de que a maioria dos secularistas acreditou, desde o século XVIII, que a história estava do seu lado e que a moderni-

\footnotetext{
${ }^{3}$ Veja-se o capítulo um (p. 23-42) do livro "Glaube als Option" (Op. Cit), do qual o presente texto corresponde ao segundo capítulo.
} 
Sociologias, Porto Alegre, ano 17, no 39, mai/ago 2015, p. 224-246

zação, no sentido de crescimento econômico e de progresso científico-tecnológico, a longo prazo levaria, inevitavelmente, ao enfraquecimento da religião ou até mesmo a seu desaparecimento. Essa ideia, deduzida por intelectuais especialmente a partir da história da França e talvez de alguns outros países da Europa Ocidental, que por vezes assumiu a forma de uma violenta ideologia de Estado sob o regime marxista da Europa Oriental, no século XX, praticamente desmoronou ao longo das últimas duas décadas, por razões internas e externas. Não pretendo aprofundar aqui as razões internas associadas a essa interpretação cognitivista ou funcionalista de crença religiosa. Entre as razões externas para este colapso, a mais importante é a crescente percepção de que a suposta relação entre a modernização e secularização não se repete fora da Europa, exceto em algumas das chamadas sociedades coloniais (Nova Zelândia, Uruguai entre outras). Nessa perspectiva, os EUA, com a sua enorme vitalidade religiosa, é cada vez menos considerado um caso especial que demande explicação. Da mesma forma, a modernização em outras partes do globo não conduz, em todos os aspectos, à secularização e, portanto, a história da secularização europeia apresenta-se cada vez mais como um evento contingente. Esses resultados empíricos, evidentemente, não devem impedir ninguém de acolher e apoiar processos de secularização. Mas com o ocaso da tese da secularização, o secularismo terá de sobreviver sem garantias fundadas na filosofia da história e precisará justificar-se de outra forma, não mais em uma narrativa do progresso.

Mas eu me referi ao fim de duas certezas aparentes. É importante para mim evitar qualquer tom triunfalista ao afirmar que a tese da secularização é coisa do passado, por isso devo acrescentar de imediato que também a velha antítese apologética religiosa parece ter chegado ao seu fim. Enquanto secularistas preferem acreditar na tese da secularização, os fiéis tendem a afirmar - pelo menos desde que a fé religiosa foi forçada à 
defensiva, sobretudo, pela ascensão da opção secular - que a fé é indispensável para a saúde mental, a motivação moral e/ou a coesão social. Portanto, em certa medida, eles alertam contra a secularização, como sendo uma ameaça para a saúde, a moralidade e a paz.

No entanto, por razões tanto internas como externas, também esta teoria parece ter chegado ao seu fim. Como razões internas, vejo uma noção que considero irrefutável da possibilidade de existirem relações empiricamente demonstráveis entre religião e saúde mental, orientação moral, etc., que parecem lógicas pelo simples fato de as religiões desaconselharem certos comportamentos de risco e antissociais e oferecerem alternativas às pessoas. Mas ninguém irá adotar uma fé religiosa com base na percepção racional desses vínculos. A simples constatação de que isso seja possível, relegaria a crença religiosa a uma terapia autossugestiva. Por outro lado, com a menção a razões "externas", refiro-me a que a atual emergência de sociedades em grande parte secularizadas, em certo sentido, nos permite testar empiricamente os prognósticos dos apologistas da fé religiosa. Quando os analistas do século XIX afirmavam que sem fé em Deus tudo seria permitido e, portanto, a moral e a coesão social seriam impossíveis, na verdade, ainda não existiam sociedades secularizadas; tudo o que havia nesse sentido era alguns ambientes nacionais proletários e liberais, que se mostravam hostis à religião ou distanciados da fé religiosa. Só a partir do final da década de 1960 em partes da Europa Ocidental, e do final da década de 1950 em partes da Europa Oriental (incluindo a RDA), é que se pode falar de sociedades com alto grau de secularização. Nesse sentido, uma secularização abrangente representa uma novidade histórica.

No entanto - colocando nos termos de William James - até o momento, a decadência moral não se apresentou nas sociedades mais afetadas (as outrora comunistas, como a antiga Alemanha Oriental, a Repú- 
Sociologias, Porto Alegre, ano 17, no 39, mai/ago 2015, p. 224-246

blica Tcheca, a Estônia, e as ocidentais como Grã-Bretanha, Suécia, entre outras). Assim como a ausência de secularização no mundo em processo de modernização fora da Europa depõe contra a tese da secularização, também a ausência de decadência moral nas sociedades altamente secularizadas da Europa contradiz a tese de que a secularização tenderia a corroer a moral. No âmbito do debate público, a perda da fé é com frequência imediatamente diagnosticada como a causa de crimes ou abusos - como em casos revoltantes de infanticídio, delinquência juvenil ou corrupção -, mas, da perspectiva das ciências sociais isso é evidente amadorismo. Para poder reivindicar validade causal, tais afirmações precisariam ser corroboradas através de comparações históricas ou internacionais, e não tenho conhecimento de qualquer estudo sério que o tenha feito. Pelo contrário, em sociedades com alto grau de religiosidade, com frequência se encontra corrupção - basta pensar no "familismo amoral" do sul da Itália (Edward Banfield). Apesar da já mencionada intensidade da vida religiosa nos Estados Unidos, segundo vários indicadores, o nível de violência naquele país é cerca de cinco vezes mais elevado que a média europeia (JOAS; KNÖBL, 1994). Embora

um número significativo de estudos empíricos nos EUA tenha demonstrado que estadunidenses moderadamente religiosos apresentam maiores graus de bem-estar subjetivo e satisfação com a vida, mais satisfação no casamento, meIhor coesão familiar e menos sintomas depressivos do que os não religioso (ZUCKERMAN, 2010, p. 18),

alguns estudos comparativos concluíram

que nações com altos índices de fé em Deus também apresentavam altas taxas de homicídio, e de mortalidade de adolescentes e jovens, maiores índices de doenças sexualmente transmissíveis, gravidez na adolescência e abortos do 
Sociologias, Porto Alegre, ano 17, no 39, mai/ago 2015, p. 224-246

que as nações em que a crença em Deus é relativamente baixa (Idem., p. 193) ${ }^{4}$.

Meras correlações entre religião e criminalidade etc. não são adequadas para responder questões causais. À primeira vista, parece não ser possível prover explicações causais com base na religião para as deficiências morais, seja no sentido positivo ou no negativo.

Por tanto, minha questão - se existiria uma evidência empírica inequívoca de que a secularização conduz à decadência moral - pode, até agora, ser respondida, sem mais delongas, com um sonoro não. Mais interessante do que esse resultado, entretanto, é refletir sobre as razões para isso. A refutação da tese da secularização pode estimular-nos a refletir sobre em que consiste, efetivamente, a fé, e a pensar em como poderíamos rever nossa concepção de modernização, se já não consideramos a secularização seu corolário inevitável. Da mesma forma, a crescente implausibilidade da tese da força destrutiva da secularização em relação à moral pode ser a oportunidade para examinarmos de um novo modo os vínculos entre moral e religião.

Pretendo fazer isso aqui em quatro etapas. Em primeiro lugar, me pergunto se, em sociedades secularizadas, a moral seria um mero eco de tradições religiosas. Em seguida, com referência a sociedades tribais, examinarei brevemente se, em princípio, é válida a noção de que a religião exerce um papel constitutivo da moral. Depois, a partir de um exemplo do trabalho missionário cristão, tratarei brevemente da interação entre novas religiões e a moral tradicional. No final, sintetizarei essas considerações em uma hipótese sobre as duas origens da regulação normativa e

${ }^{4}$ Nota 55 com referência a "Cross-National Correlations of Quantifiable Societal Health with Popular Religiosity and Secularism in the Prosperous Democracies" (PAUL, Gregory, 2005). Um bom panorama em Bernhard Spilka et al., (2009, p. 416-479). 
Sociologias, Porto Alegre, ano 17, no 39, mai/ago 2015, p. 224-246

identificarei a área em que vislumbro, atualmente, um risco de retrocesso moral por meio da secularização.

\section{Moral como eco?}

Visto que a secularização, em particular a das mulheres, é um fenômeno histórico relativamente recente ${ }^{5}$, é quase impossível fazer uma afirmação empiricamente fundamentada sobre os efeitos multigeracionais de longo prazo, dos processos de secularização, sobre as orientações morais, se não quisermos ficar restritos ao nível mais superficial - ou seja, às definições normativas para questões individuais de estilo de vida, nas quais há diferença marcante entre a doutrina eclesial e o consenso contemporâneo (como no caso da contracepção). A medição dessas definições é relativamente fácil. Se, por outro lado, estivermos interessados nas dimensões mais fundamentais do julgamento moral, é preciso fazer um desvio e analisar as estruturas subjacentes aos juízos morais, assim como a persistência de distinções religiosas como, por exemplo, especificidades confessionais, ao longo de um determinado período de tempo. Um dos estudos mais interessantes desse tipo é de Andrew Greeley (1989, p. 485-502). Com base no trabalho do célebre teólogo de Chicago, David Tracy, ele estabeleceu uma distinção dicotômica entre o "imaginário" protestante e o católico, portanto, entre visões de mundo confessionalmente moldadas. A proposição contida nessa dicotomia e de que, embora essas visões de mundo produzam códigos teológicos e éticos, elas próprias seriam pré-proposicionais e metafóricas. Sob essa hipótese, diferenças entre determinadas doutrinas e concepções éticas não constituem o nível verdadeiramente definidor da distinção entre as confissões, sendo apenas

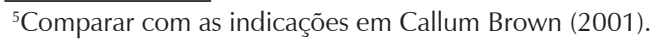


Sociologias, Porto Alegre, ano 17, no 39, mai/ago 2015, p. 224-246

manifestações de uma diferença mais fundamental no simbolismo dominante. Os termos utilizados por Tracy para as diferenças são "analógicas" versus "dialéticas". A visão de mundo analógica (católica) aceita um Deus que se manifesta em e através de sua criação, de modo que tudo no mundo faz parte do divino; a visão de mundo protestante, ao contrário, vê o mundo como radicalmente diferente de Deus, sendo que Deus se manifesta raramente no mundo, particularmente através de Jesus Cristo. Para os católicos, as relações sociais naturais seriam elas próprias testemunho da presença de Deus no mundo; para os protestantes, no entanto, o indivíduo só alcança sua plenitude humana através de sua relação sincera com Deus, enquanto a sociedade está distante de Deus. Essas noções conflitantes de individualidade e de sociabilidade, por sua vez, seriam o ponto de partida para atitudes muito diferentes em relação ao papel da religião institucionalizada e a toda uma gama de questões éticas e políticas. Essas diferenças são particularmente intensas no campo da educação:

protestantes valorizarão em seus filhos as virtudes da iniciativa própria, da integridade, do zelo ao trabalho e da economia mais que os católicos; enquanto os católicos darão grande valor à lealdade, obediência e paciência. Com grande probabilidade, os protestantes reclamarão dos vícios que comprometem a integridade pessoal, a honestidade e o senso de dever. Para os católicos as ações mais ofensivas serão, provavelmente, as, que infligem danos às redes de relacionamentos - adultério, prostituição, suicídio. (Idem, p. 487)

Poder-se-ia destacar ainda que o papel das intenções parece variar entre as confissões - especificamente com relação a se boas intenções ou ações por si sós são decisivas para avaliar a qualidade moral de uma ação; e pelo fato de o status das afirmações morais ser interpretado de forma diferente, dependendo dessas serem consideradas como normas ou como ideais. 
Sociologias, Porto Alegre, ano 17, no 39, mai/ago 2015, p. 224-246

É evidente - e tanto Tracy como Greeley têm consciência disso - que as principais controvérsias teológicas no Cristianismo não podem ser esquematizadas de um modo dicotômico e simplista como esse. Vale observar, também, que ao descrever o protestantismo, por óbvio, esses autores tinham em mente as variantes dominantes nos países de fala inglesa e que o luteranismo alemão ou escandinavo ocupavam uma posição intermediária. Mas isso não é o que importa aqui, e sim a questão da persistência de tais "imaginários" religiosos profundamente arraigados. Constatou-se, a partir da base de dados do "International Study of Values", na década de 1980, que em 21 das 36 variáveis pesquisadas existem de fato correlações estatisticamente significativas entre denominação e orientação segundo valores, e todas na direção presumida. Não houve correlações contrárias. Em todos os países pesquisados, os protestantes enfatizaram liberdade e individualismo, enquanto os católicos destacaram igualdade e justiça, etc. Nos países de língua inglesa, as diferenças foram mais acentuadas do que no continente europeu, embora em graus muito variados. Em comparação com Reino Unido, Irlanda, Canadá e Austrália, elas se mostraram menores nos Estados Unidos, o que pode estar associado, em todos esses países (exceto a Austrália), a diferenças étnicas e ao grau em que as diferenças confessionais afetam (e vice-versa) diferentes grupos. Mas o mais importante para nossos propósitos, porém, é a constatação de que essas diferenças não diminuem quando se consideram somente os entrevistados mais jovens (Idem, p. 493). Com isso, pode-se descartar a hipótese de que novas gerações de pessoas de fé pudessem exibir uma mudança de valores fundamentais tal que suas novas atitudes já não seriam nutridas pelos imaginários fundamentais, profundamente arraigados em sua visão de mundo religiosa.

Contudo, se isso é verdade, e de forma tal que as pessoas afetadas sequer tenham consciência disso, então é provável que esses imaginários 
arraigados tenham influência até mesmo sobre aquelas pessoas que romperam com as orientações religiosas que as formaram. Nesse caso, não se trataria simplesmente de uma visão de mundo secular que pudesse ser confrontada com as cosmovisões religiosas. Isso significa que suas origens em um imaginário religioso seriam inerentes às visões de mundo seculares, seja porque supostas certezas da visão de mundo religiosa são legadas no processo de secularização, seja porque uma rejeição específica de elementos da cosmovisão religiosa é decisiva, como uma espécie de contra-identificação, para a referida cosmovisão secular. Há uma variedade de secularismos, assim como existe uma variedade de religiões.

Essa suposição daria sentido a observações que apresentam a fortemente secularizada cultura moral e política da Suécia como inteiramente luterana, ou o stalinismo soviético, em termos de seus simbolismos (Bildkultur), em muitos aspectos como um remanescente de modelos do cristianismo ortodoxo. (Há também a conhecida história de um pedestre que, ao transpor a linha divisória entre católicos e protestantes em uma pequena cidade da Irlanda do Norte, com uma arma apontada para ele, é interrogado sobre sua confissão, respondendo que é ateu. E ainda precisa lidar com a seguinte pergunta: ateu católico ou protestante?). Assim, aparentemente, persistem estruturas fundamentais de percepção moralmente relevantes por longos períodos de tempo em que, mesmo sob condições da secularização, um imaginário mais antigo pode seguir orientando a moral - quando a secularização não emprega coação e violência contra desvios específicos deste imaginário.

Uma afirmação empiricamente fidedigna de qual seria o impacto moral da secularização massiva ao longo de várias gerações, não poder ser feita ainda. Para tanto, duas outras considerações seriam importantes. Primeiro, as motivações para o secularismo podem ter alto conteúdo moral. É ridículo, quando os assim chamados novos ateus, como Richard 
Sociologias, Porto Alegre, ano 17, no 39, mai/ago 2015, p. 224-246

Dawkins e Daniel Dennett, tratam as pessoas religiosas de tolas e limitadas, mas, é claro, é igualmente ridículo, quando pregadores evangélicos tentam mostrar, nos Estados Unidos, que ateus são arbitrários, insensatos, ignorantes, inconsistentes, irresponsáveis, indecentes, insensíveis e, principalmente, imorais (SINNOTT-ARMSTRONG, 2009). Os grandes ateístas do século XIX lutaram, muitas vezes, contra o Cristianismo, ou porque viam na esperança da vida após a morte uma forma de desviar a atenção da busca de uma vida melhor neste mundo e um empecilho a viver a vida intensamente, ou porque suspeitavam que a moral cristã acarretava sentimentos de culpa desnecessários, uma rejeição compulsiva da própria corporeidade e hipocrisia nas relações interpessoais. Tais perspectivas, sejam elas legítimas ou ilegítimas, obviamente expressam motivos profundamente morais. O mesmo vale, hoje, para aqueles que argumentam contra a religião, sempre que o façam não sob cegueira ideológica e com nítido interesse na fé vivida. Na Alemanha atual, contudo, o normal é um ateísmo ingênuo, corriqueiro, habitual. Já no ano de 1895, o grande teólogo protestante Ernst Troeltsch - amigo e rival de Weber - afirmou que a ética ateísta somente alcançaria os resultados que prometia se fosse julgada por uma ética religiosa específica, a qual ela quisesse superar. Sem essa perspectiva de comparação, ela perde, com frequência, sua força motivadora e o seu caráter nobre (TROELTSCH; ETHIK, 1895). Os acontecimentos nos países ainda fortemente seculares da Europa pós-comunista parecem confirmar a afirmação de Troeltsch. Contudo, sem distinguir a profundidade moral das diversas formas de ateísmo, não se podem fazer afirmações sobre as consequências morais da secularização.

Além disso, pesquisas recentes ${ }^{6}$ mostram que, nos Estados Unidos, a grande maioria das crianças que não se criaram em contextos religiosos

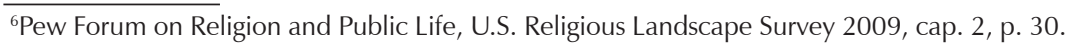

http://dx.doi.org/10.1590/15174522-017003907 
Sociologias, Porto Alegre, ano 17, no 39, mai/ago 2015, p. 224-246

desenvolveram vínculos religiosos no decorrer de suas vidas. Para colocar em termos sociológicos, os religiosamente independentes apresentam uma das mais baixas "taxas de retenção"; mesmo a minoria dos educados sem uma afiliação religiosa, e que como adultos ainda não se filiaram a nenhuma comunidade religiosa, deixam em aberto a possibilidade de uma mudança. Na grande maioria dos casos, elas não se veem como ateístas convictas, mas apenas como pessoas que ainda não encontraram a comunidade religiosa certa. Isso se aplica apenas aos Estados Unidos, fortemente marcado pela religiosidade, mas não para as sociedades europeias secularizadas, embora o significativo papel das escolas cristãs na Alemanha Oriental pós-comunista também possa ser considerado uma abertura em uma ordem secularizada praticamente homogênea. Isso mostra, de qualquer forma, que também a questão das consequências morais da secularização muda quando estamos preparados para pensar além da secularização como um processo irreversível. Em uma sociedade de forte característica religiosa, a falta de fé pode ser um simples fenômeno geracional, sem efeitos de longo prazo. Mas mesmo em sociedades que permaneceram por algum tempo sob pressão secularizadora extrema (como a República Popular da China) não estão descartados dramáticos processos de revitalização religiosa.

\section{Uma fonte não religiosa da moral}

Até o momento, o discurso girou em torno do fato de que orientações morais muitas vezes são alimentadas por um profundo imaginário de difícil conceitualização. O olhar a seguir sobre a moral em "sociedades tribais" tem, por outro lado, outro efeito conclusivo. Trata-se, aqui, de comprovar que existem estruturas fundamentais de reciprocidade vivenciada que, em si, representam uma fonte da moral e como tal não são determinadas pelo imaginário religioso. 
Quero exemplificar isso a partir da clássica pesquisa de Bronislaw Malinowski "Crime e Costume na Sociedade Selvagem", dos anos 19207. Em função de sua pesquisa de longos anos sobre os melanésios das llhas Trobriand, Malinowski opôs-se a duas ideias antes dominantes: a de que os "selvagens", como o termo sugere, não conheciam regras ou, se elas existiam, seguiam-nas somente por capricho ou com pouca seriedade (Idem, p. 16); e, a ideia de que em "tribos" o sentimento de grupo seria tão forte, que só seria possível a total obediência aos costumes e às leis, as quais alcançavam as questões mais particulares do dia a dia. A essas duas ideias, muitas vezes defendidas por pesquisadores sem qualquer conhecimento primário sobre a vida tribal, Malinowski opôs uma análise que inicia pela vida econômica - concretamente, no pescar em comunidade. Ele descreve detalhadamente como a pesca em comunidade no mar exige o emprego de grandes canoas, nas quais muitos homens precisam trabalhar em conjunto e esperam receber sua parte na divisão da pescaria. Dessa forma, o direito de propriedade e uso da canoa consiste de uma série de compromissos e deveres que unem um grupo de pessoas em um grupo de trabalho (Idem, p. 23). Comprova-se que há

um sistema definido de distribuição das funções e um rígido sistema de deveres recíprocos, no qual o sentido de dever e o reconhecimento da necessidade de cooperação estão lado a lado com a realização do próprio interesse, e proveito dos privilégios e dos benefícios [...] É a soma de deveres, privilégios e reciprocidades que une os proprietários comunitários ao objeto e entre si (Idem, p. 25).

Um mecanismo semelhante ao dos pescadores cooperativos pode ser observado também na relação das vilas pesqueiras com suas vizinhas do interior. Nesse caso, são mantidas relações de troca complexas - como

${ }^{7}$ Um ótimo aprofundamento desta questão é oferecido por Marshall Sahlins, (1972). 
Sociologias, Porto Alegre, ano 17, no 39, mai/ago 2015, p. 224-246

a troca de legumes por peixe, distribuída de acordo com os ciclos do ano -, nas quais cada comunidade detém uma arma para assegurar seus direitos: a reciprocidade (Idem, p. 27). Os parceiros de trocas, muitas vezes, estão unidos entre si em vários níveis, inclusive por relações de casamento. Como em todas as regras de reciprocidade baseadas em considerações de uso, também estas estão ameaçadas de constantes desvios por oportunistas. Por outro lado, tais normas são elásticas e permitem uma considerável margem de interpretação e cumprimento. Malinowski conclui que, junto a uma legislação penal religiosamente fundamentada, único objeto do interesse do grande sociólogo francês Émile Durkheim (1992) em sua obra clássica sobre a história da divisão do trabalho, a reciprocidade constitui o fundamento de toda a estrutura social. Por mais importante que fosse o quase-direito penal desses povos "primitivos", não é tudo; entre eles também há um quase-direito civil:

Em todas as sociedades, é preciso haver uma classe de normas que sejam práticas demais para serem mantidas por sanções religiosas; onerosas demais para ficarem a critério da boa vontade; e por demais vitais ao interesse pessoal para submeter as pessoas através de algum agente abstrato (MALINOWSKI, 1948 [1926], p. 63).

O passo de Malinowski convergiu, aliás, com as impressões sobre a importância fundamental do ato de dar para a criação e a manutenção das relações sociais, na obra de seu amigo Marcel Mauss, sobrinho de Durkheim. Dar não se orienta puramente pela utilidade, como na troca, nem é um ato puramente caritativo, mas sim constitutivo de relações (MAUSS, 1968 [1923]; HÉNAFF, 2009). Esses estudos representam uma espécie de contrapartida filogenética dos resultados ontogenéticos na psicologia do desenvolvimento de Jean Piaget, Lawrence Kohlberg e seus alunos. Também nesses trabalhos, evidencia-se que as crianças podem "descobrir" regras morais fundamentais - como a lealdade no jogo - de 
Sociologias, Porto Alegre, ano 17, no 39, mai/ago 2015, p. 224-246

forma autônoma e sem influência de autoridades educadoras, a partir da reflexão sobre as condições para lograr brincar juntas (PIAGET, 1973; KOHLBERG, 1974). Com isso, é possível confirmar - sem necessariamente nos aprofundar nessas pesquisas famosas - que a reciprocidade constitui uma fonte de moral, a qual não está fundamentada em imaginários religiosos e, portanto provavelmente não será diretamente afetada por processos de secularização.

\section{Decadência moral através da religião?}

Contudo, há limites para a reciprocidade. Por um lado, a reciprocidade direta só é suficiente sob condições muito simples, que evidentemente não se observavam sequer nas sociedades tribais descritas por Malinowski. Se uma terceira parte se agrega a uma cadeia de interação $a-b-c$, já se estabelece um problema de circulação e garantia. Se eu espero a compensação adequada não de meu parceiro imediato, mas de um terceiro, e só depois de um certo tempo, isso abre possibilidades de desvio, e a confiança na manutenção de regras assume maior importância. Atualmente, essas questões vêm sendo analisadas em profundidade por correntes teóricas baseadas em modelos de ação utilitarista (JOAS; KNÖBL, 2004, p. 143-182).

Por outro lado, há limites na reciprocidade colocados pela finitude de nosso tempo de vida. Minha fórmula preferida para comunicar essa ideia é dada pela lenda do beisebol americano Yogi Berra: vá sempre aos enterros dos outros, do contrário, eles não irão ao seu. Por que devemos nos sentir obrigados a legar aos nossos filhos o amor que recebemos de nossos pais? Este é o ponto em que muitos afirmam que uma moral da reciprocidade seria necessariamente instável, necessitando reforço de uma fundamentação religiosa. 
Sociologias, Porto Alegre, ano 17, no 39, mai/ago 2015, p. 224-246

Considero essa ideia plausível, na medida em que compromissos de valor adicionais, independentes do contexto e duradouros, assim como o valor da justiça, certamente podem evitar recusas utilitaristas de reciprocidade, como por exemplo, no comportamento oportunista. Mas, primeiramente, tal compromisso de valor não precisa ser mais do que um vínculo com as regras reflexivamente estabelecidas de cooperação leal como tal - por exemplo, através do compromisso com a regra de ouro ou, em um nível mais alto de reflexão, com o imperativo categórico. Ainda que seja equivocada, como frequentemente se presume ter sido a crença de Kant, e como o jovem Habermas de fato acreditava, a ideia de que a força da motivação racional nesse sentido seja forte e suficiente, isso não significa que somente a motivação religiosa possa conferir estabilidade. Uma força assim forte pode ser, em geral, inerente a valores fortes, saturados de experiência, inclusive os decorrentes de experiências de cunho negativo. A prova subjetiva da natureza intolerável do sofrimento e da degradação certamente pode levar a desejos de vingança e a espirais de violência, mas também, ao invés disso, a compromissos com valores como dignidade humana e não-violência - e, de uma perspectiva histórico-empírica, aplica-se evidentemente também a pessoas sem vínculos religiosos. A história dos direitos humanos exibe uma complexa interação religiosa-secular. Para ser adequadamente compreendida, essa história não pode ser considerada cristã nem anticristã ${ }^{8}$.

Além disso, a influência das religiões nas estruturas fundamentais de reciprocidade de uma sociedade de modo algum deve ser de estabilização moral. Para ilustrar este ponto, usarei um exemplo da literatura que, contudo, tem um caráter praticamente etnológico. Trata-se do conto Am Ende der Welt [No fim do mundo ${ }^{N T}$, (1875/76), do grande contista cristão

\footnotetext{
${ }^{8}$ Sobre isso, ver Hans Joas (2011).

NT O conto ainda não está publicado na língua portuguesa. Agradeço à colega Denise R. de Sales, colega do Setor de Russo da UFRGS pela informação (Nota do tradutor).
} 
Sociologias, Porto Alegre, ano 17, no 39, mai/ago 2015, p. 224-246

russo Nikolai Leskow (1984, p. 103-183). O conto trata dos fracassos do trabalho missionário ortodoxo-russo na Sibéria e na Ásia Central. A estrutura narrativa sugere, inicialmente que a falta de sucesso do trabalho missionário ortodoxo em comparação aos missionários protestantes, provenientes do exterior e recém admitidos no Império Russo, só poderia ser explicada pelo baixo grau de formação e pelo raciocínio lento do clero russo. Mas, então, um bispo conta como tentou desvendar essas falhas através de viagens de inspeção e como constatou, para seu espanto, que justamente os melhores e mais inteligentes religiosos desenvolviam, depois de algum tempo, as maiores dúvidas no trabalho missionário. Preso em uma terrível nevasca, o bispo viveu na própria pele a experiência comovente de receber ajuda de um integrante não batizado de uma tribo, enquanto um padre que o acompanhava foi cruelmente abandonado por outro membro da tribo que fora batizado. Ele descobre que o batismo individual desvincula os integrantes de tribos de suas obrigações sociais, o que leva um deles a se deixar batizar repetidamente, sob diferentes nomes, para assim poupar seus companheiros de tribo do mesmo destino, o da perda da confiança dos outros. E, acima de tudo, ele descobre que os recém-batizados podem usar sua confissão para justificar o abandono de seus compromissos de reciprocidade. Transgressões (Missetaten), que antes seriam obviamente compensadas através da reciprocidade, agora eram eximidas pela confissão. Naturalmente, é fácil atribuir isso à mera incompreensão da confissão e do batismo, mas o que Leskow quer mostrar é que muito do que se considera sucesso missionário não se justifica se entendermos verdadeiramente a mensagem cristã. Aqui, não é a secularização, mas o trabalho missionário que conduz à decadência moral. Esse problema, aliás, não está limitado a sociedades tribais. Se a fé em Cristo for desgarrada de todos os contextos tradicionais e sociais, inevitavelmente ela se diluirá a ponto de tornar-se não mais que uma simples 
Sociologias, Porto Alegre, ano 17, no 39, mai/ago 2015, p. 224-246

receita de redenção individual, o que sugere consequências destrutivas para a moral. ${ }^{9}$

\section{Duas origens da moral}

Essas reflexões empiricamente fundadas sobre a suposta imprescindibilidade da religião para a moralidade podem ser resumidas da seguinte maneira: até agora, na é possível demonstrar que a secularização conduza à decadência moral. Em parte, isso pode resultar da persistência de orientações morais que emanam de um imaginário religioso, mas que mantêm sua força apesar de desligadas dessa base de formação. Contudo, parece ser decisivo que as próprias estruturas de cooperação humana ou conduzem os indivíduos à manutenção de compromissos de reciprocidade por razões de interesse próprio ou os sensibilizam para o valor da justiça. Este e outros valores moralmente relevantes podem inspirar compromisso através de experiências positivas - sua incorporação em modelos, por exemplo - ou de experiências negativas - como a vivência de injustiça, degradação ou violência. Como argumentei no capítulo final de meu livro "A gênese dos valores" (JOAS, 1997, p. 252-293), na história da humanidade, a moral teve sempre duas raízes: por um lado, valores e experiências constitutivas de valor e, por outro lado, a reflexão sobre as condições de cooperação. Sistemas normativos concretos resultam de ambas as fontes, da concretização de valores e da abstração da cooperação. Certamente, em suas situações particulares de ação, os atores devem observar ambos os pontos de vista, o do bom e o do justo. A redução ao justo é tão unilateral como a redução ao bom; inadmissível, também, é uma redução do bom aos imperativos religiosos.

${ }^{9}$ Ver Robert Bellah (2006, p. 474-489). Aprofundamento sobre a compreensão crista de reciprocidade: Heinrich Bedford-Strohm (1999, em especial p. 237-284). 
Por isso, apesar de toda a simpatia, em princípio, pelos objetivos do frustrado plebiscito e referendo de Berlin "Pro Reli", de 2006-2009, eu não pude concordar com o slogan usado "Valores precisam de Deus" [Werte brauchen Gott]. Pessoas de fé certamente não conseguem articular seus valores sem uma referência a sua fé; mas esta articulação de fé também deveria ser um convite às pessoas que não creem a pelo menos considerarem os valores das que creem, se não sua fé; e não deveria negar-lhes a possibilidade de encontrar seu caminho para esses valores por meio de outras rotas que não essa fé. Parece-me que a mais importante frente de discussão sobre as controvérsias morais e políticas, hoje, não se dá entre crentes e não-crentes, mas entre universalistas e antiuniversalistas, ambos os grupos incluindo pessoas religiosas e não religiosas. Embora seja fato que o potencial universalista do Cristianismo está permanentemente sob risco, eu, particularmente, vejo na mensagem do evangelho o mais forte "imaginário" de universalismo já legado à humanidade. Eu sei que outros concedem um status semelhante à filosofia de Kant ou a outras formas de argumentação filosófica e, portanto, as concebem não tanto como articulação de valores historicamente produzidos, com é o meu caso, mas como sua fundamentação racional, concebida em um determinado momento, mas válida intemporalmente e independente do contexto. Para essas pessoas, pensadores como Kant e Habermas são figuras carismáticas, porque em lugar de solucionar um problema intelectual, esses pensadores estabeleceram um fundamento moral. Dotar a obra de Kant desse significado, não me parece fazer justiça nem a ele nem ao possível alcance da fundamentação argumentativa em geral. Pode-se, sem dúvida, discordar sobre o diferente sentido da justificação com relação à fé religiosa ou à argumentação racional. Minha preocupação não está no fato de que a secularização destrói a moral como tal, mas em que um enfraquecimento do Cristianismo enfraquece um dos pilares do univer- 
Sociologias, Porto Alegre, ano 17, no 39, mai/ago 2015, p. 224-246

salismo moral e jurídico. Se este universalismo veio ao mundo historicamente associado a representações de transcendência, como afirmado na tese da Era Axial, de Karl Jaspers $(1949)^{10}$, não há segurança de que ele (o universalismo) sobreviva à perda dessas noções, de seu fundamento original. Mas uma preocupação não é o mesmo que um grito de batalha.

Hans Joas - Professor do Departamento de Sociologia da Universidade de Chicago, membro da Comissão do Pensamento Social. Ernst Troeltsch Professor de Sociologia da Religião, da Faculdade de Teologia, Humboldt Universidade de Berlim.>hans.joas@frias.uni-freiburg.de

\section{Referências}

1. BEDFORD-STROHM, Heinrich. Gemeinschaft aus kommunikativer Freiheit. Gütersloh, 1999.

2. BELLAH, Robert. Religious Pluralism and Religious Truth. In: BELLAH, R.; TIPTON, Steve (Orgs.). The Robert Bellah Reader. Durham/N. C. 2006, p. 474-489.

3. BROWN, Callum. The Death of Christian Britain. Understanding Secularisation 1800 -2000. London: 2001.

4. DURKHEIM, Emile. Über soziale Arbeitsteilung (1893). Frankfurt/Main, 1992.

5. GREELEY, Andrew. Protestant and Catholic. Is the Analogical Imagination Extinct? In: American Sociological Review, 54, 1989, p. 485-502.

6. HÉNAFF, Marcel. Der Preis der Wahrheit. Gabe, Geld und Philosophie. Frankfurt/Main 2009.

7. JAMES, William. Die Vielfalt religiöser Erfahrung (1902). Frankfurt/Main, 1997.

8. JASPERS, Karl. Vom Ursprung und Ziel der Geschichte. Zürich, 1949

9. JOAS, Hans; KNÖBL, Wolfgang (Orgs.). Gewalt in den USA. Frankfurt/Main, 1994.

${ }^{10}$ Para mais sobre esta tese, de uma das fundamentais mudanças científico-religiosas entre 800 e 200 a. C., ver Joas, 2012, em especial capítulos 8 e 10. 
Sociologias, Porto Alegre, ano 17, no 39, mai/ago 2015, p. 224-246

10. JOAS, Hans; KNÖBL, Wolfgang. Sozialtheorie. Frankfurt/Main, 2004.

11. JOAS, Hans. Die Entstehung der Werte. Frankfurt/Main, 1997.

12. JOAS, Hans. Braucht der Mensch Religion? Über Erfahrungen der Selbsttranszendenz. Freiburg 2004.

13. JOAS, Hans. Die Sakralität der Person. Eine neue Genealogie der Menschenrechte. Berlin, 2011.

14. JOAS, Hans. Glaube als Option - Zukunftsmöglichkeiten des Christentums. Herder, Freiburg/Basel/Wien, 2012.

15. KOHLBERG, Lawrence. Strafe und Sequenz. Sozialisation unter dem Aspekt der kognitiven Entwicklung. In: KOHLBERG, Lawrence. Zur kognitiven Entwicklung des Kindes. Frankfurt/Main, 1974.

16. LESKOW, Nikolai. Am Ende der Welt. In: LESKOW, Nikolai. Der ungetaufte Pope. Erzählungen, Berlin 1984.

17. MALINOWSKI, Bronislaw. Sitte und Verbrechen bei den Naturvölkern (1926). Bern, 1948.

18. MAUSS, Marcel. Die Gabe (1923). Frankfurt/Main, 1968.

19. PAUL, Gregory. Cross-National Correlations of Quantifiable Societal Health with Popular Religiosity and Secularism in the Prosperous Democracies. In: Journal of Religion and Society 7, 2005, p.1-17.

20. PIAGET, Jean Piaget. Das moralische Urteil beim Kinde. Frankfurt/Main, 1973.

21. SAHLINS, Marshall. Stone Age Economics. New York, 1972.

22. SINNOTT-ARMSTRONG, Walter. Morality without God? Oxford, 2009, S. XVIII.

23. SPILKA, Bernhard et al.. The Psychology of Religion. An Empirical Approach. New York: 2009.

24. TROELTSCH, Ernst; ETHIK, Atheistische (1895). In: TROELTSCH, Ernst. Gesammelte Schriften 2. Tübingen, 1912.

25. ZUCKERMAN, Phil. Society without God. What the Least Religious Nations Can Tell Us About Contentment. New York, 2010.

Recebido em: 10/09/2014

Aceite Final: 17/10/2014 